\title{
Effect of mastitis during the first lactation on production and reproduction performance of Holstein cows
}

\author{
Alireza Heravi Moussavi • Mohsen Danesh Mesgaran • \\ Robert O. Gilbert
}

Accepted: 10 February 2012 / Published online: 23 February 2012

(C) Springer Science+Business Media B.V. 2012

\begin{abstract}
The aim of this study was to evaluate the effect of postpartum mastitis between first calving and subsequent conception on production and reproduction performance as well as culling of Holstein cows. A data set of 9,183 first lactation cows was used. Results showed that the first cumulative 100 days' milk production and the milk yield standardized to 305 days were affected by the interval from calving to first mastitis $(P<0.05)$. Cows with one episode of mastitis produced more milk than those with repeated episodes of mastitis $(P<0.01)$. Increase in the number of mastitis episodes and also decrease in interval between first calving and mastitis increased services per conception $(P<0.001)$. Mastitis episode and the interval between calving and first mastitis had no apparent impact on the calving to conception interval $(P>0.05)$. Calving year, calving difficulty score, and cumulative first 60 days milk production had significant impacts on mastitis risk $(P<0.05)$. The interval from calving to the first incidence of mastitis decreased over the period studied $(P<0.001)$. Productive life tended to be decreased due to mastitis $(P=0.07)$. Survival analysis showed a significant difference between the lengths of productive life for cows with different intervals from calving to first mastitis $(P<0.01)$. The results demonstrated that clinical mastitis between first calving and conception reduced production and reproduction performance with an increase in chance of culling.
\end{abstract}

\footnotetext{
A. Heravi Moussavi $(\bowtie) \cdot$ M. Danesh Mesgaran Department of Animal Science, Ferdowsi University of Mashhad, Mashhad 91775-1163 Khorasan Razavi, Iran

e-mail: bbheravi@yahoo.com

R. O. Gilbert

Department of Clinical Sciences, Cornell University, Ithaca, NY 14853, USA
}

Keywords Dairy cows · Mastitis · Production · Reproduction $\cdot$ Culling

\section{Introduction}

The future production of a dairy herd depends largely on primiparae. A healthy start of the lactation cycle is essential to recover the investment made during heifer rearing. Bovine mastitis is defined as inflammation of the mammary gland. Previous studies showed how mastitis in primiparae could be a costly disease and detrimental to farm economy (Huijps et al. 2009). In fact, subclinical and clinical mastitis during development of the mammary gland and in early lactation may adversely affect future milk quality and quantity, udder health and necessity to cull. Signs of clinical mastitis include alterations in milk composition and appearance, decreased milk production, elevated body temperature, and swelling, redness, or heat in infected quarters.

In addition, clinical mastitis affects reproductive performance, resulting in an increase in the number of days to first service, days open, and services per conception (Ahmadzadeh et al. 2009). It was shown that clinical mastitis has multiple actions that hinder normal endocrine function and particularly affecting communication from the pituitary to the ovary (Hockett et al. 2005). The onset of clinical mastitis was also important in terms of embryo survival (Santos et al. 2004; Hertl et al. 2010). The impact of different categories of pathogens was different among the studies as the negative effects of mastitis on reproduction were observed regardless of clinical case being caused by either Gram-positive or Gram-negative bacteria (Santos et al. 2004).

Some factors influence the incidence of clinical mastitis including herd (Nyman et al. 2007) and individual animal (Olde Riekerink et al. 2007). In an individual herd, cow 
factors are responsible for the difference among cows with clinical mastitis (Steeneveld et al. 2008).

A wide range of estimates have been reported in terms of the effect of mastitis on production and reproduction performance of dairy cows. However, none have analyzed the impact of mastitis during the first lactation on production and reproduction performance as well as necessity to cull based on all known cow factors together in one multivariate model. Recently, survival analysis was used to assess the effects of diseases on productive life. Survival analysis allows for a more appropriate management of censored data and time-dependent covariates.

The objective of this study was to evaluate the effect of postpartum mastitis between first calving and subsequent conception on production and reproduction performance as well as culling of Iranian Holstein cows.

\section{Materials and methods}

Four commercial dairy farms milking Holstein cattle in the northern region of the province of Khorasan Razavi, Iran, were used in this study. The province is located in northeastern Iran and its weather is considered dry and semi-dry. Herd sizes were 235, 416, 508, and 898 lactating cows. All herds had average milk production of $8,145 \mathrm{~kg}$ per cow per lactation on a 305-day basis (range 7,578 to $8,670 \mathrm{~kg}$ ). Cows were housed in loose barns with concrete floors and were classified by lactation and production status into feeding groups. All groups were fed a balanced total mixed ration and milked three times daily. Each farmer used the same dairy management software to record cow data and to manage operations. Ultimately, a data set of 9,183 first lactation cows calving from 1994 till 2008 from the study herds was used.

All the farm milkers were familiar with detection of clinical mastitis (CM) by examination of foremilk. Most cases of CM were identified by milkers (warm, swollen udder, or changes in the milk consistency), whereas others were detected by the herdsperson examining cows who had a concurrent drop in milk production.

The dependent variables analyzed were the cumulative first 100 days' milk production, 305-day adjusted milk yield, calving to conception interval (DO, the number of days between calving and conception), the number of services per conception (SC, defined as the number of services that a cow required to conceive), mastitis episode, calving to first mastitis interval, length of productive life (LPL), and the interval between 30 days in milk (DIM) after first calving and culling (LPL30). Cumulative first 60 days' milk production was categorized in three levels (less than 1,644, 1,645 to 2,036 , and more than $2,036 \mathrm{~kg}$ ). Conception was a subsequent pregnancy as diagnosed by a veterinarian. Failure to conceive was considered if the cow was determined to be nonpregnant by the farm veterinarian or if a subsequent breeding was reported after 17 to 24 days post-breeding. Calving to first mastitis interval was categorized in three levels (less than 10,10 to 60 , and more than 60 days between calving and first clinical mastitis). For analyzing the cumulative first 100 days' milk production, the calving to first mastitis interval was categorized in three levels: less than 10, 10 to 50 , and 50 to 100 days. The length of productive life was defined as the interval from first calving to the date of death or culling on the farm or the interval from 30 DIM after the first calving to date of death or culling on the farm (LPL30). Animal records used for the analysis had to have a date of first calving, and a date of death or culling from the herd.

Data were analyzed using standard least squares method using the statistical software package JMP (SAS Institute Inc., NC, USA). The standard least squares model is for continuous-responses fit to a linear model of factors using least squares. This method assumes that the best-fit curve of a given type is the curve that has the minimal sum of the deviations squared from a given set of data.

Besides the time of mastitis occurrence, other explanatory independent variables considered in the analysis were herd, number of mastitis episodes, 60 days milk production, calving season (summer, fall, winter, and spring), year of calving (1994 to 2008), calving difficulty score (eutocia vs. others including dystocia, stillbirth, and abortion), calf sex (male and female), and origins of sires. Year of calving was categorized in two levels (1994 to 2000 and 2001 to 2008). Sires were grouped into various categories depending on their area of origin. In total, four groups were defined; Iran, Canada, USA, and others which included sires originating from European countries. Because of the low number of sires originating from European countries, this group was omitted from final data for the statistical analysis.

Biologically plausible two-way interactions were included in preliminary models, but were removed when not significant. Least squares means are reported throughout, and significance was declared at $P<0.05$. Least squares means are predicted values from the specified model across the levels of a categorical effect where the other model factors are controlled by being set to neutral values.

Survival data were analyzed using the Kaplan-Meier method, and differences in the cumulative survival rates between subgroups were compared with log rank and Wilcoxon tests. Survival analysis calculates estimates of survival functions using the Kaplan-Meier method for one or more groups of right-censored data. We also used the log rank and Wilcoxon statistics to test homogeneity between the groups. Survival statistical analysis was performed using the statistical software package JMP (SAS Institute Inc., NC, USA). 


\section{Results}

In total, the data of 8,406 and 777 first lactating cows without and with mastitis have been used in this study. Of the mastitic cows, 641 and 136 cows had one time or two and more mastitis episodes, respectively. On average, the culling rate was $28 \%$ across herds. Cumulative 60 and 100 days milk productions averaged 1,678.8 \pm 387 and $2,793.3 \pm 635 \mathrm{~kg}$, respectively. The cumulative 60 days milk production median was $1,707.4 \mathrm{~kg}$ and $25 \%$ and $75 \%$ quartiles were $1,427.2$ and $1,951.7 \mathrm{~kg}$, respectively. The cumulative 100 days milk production median was $2,837.8 \mathrm{~kg}$ and $25 \%$ and $75 \%$ quartiles were $2,367.0$ and $3,247.2 \mathrm{~kg}$, respectively. The 305 -day adjusted milk yield averaged $7,425.3 \pm 1,937 \mathrm{~kg}$. The median was $7,539.0 \mathrm{~kg}$ and $25 \%$ and $75 \%$ quartiles were $6,151.0$ and $8,711.0 \mathrm{~kg}$, respectively.

The raw mean of calving to first clinical mastitis was $47.7 \pm 2.6$ days. The median was 25.2 days and $25 \%$ and $75 \%$ quartiles were 4 and 79.5 days, respectively. The calving to first mastitis interval decreased over the period studied $(P<0.05 ; 55.96 \pm 4.75$ vs. $44.28 \pm 3.10$ days, respectively for 1994-2000 and 2001-2008).

First cumulative 100 days' milk production and milk yield standardized to 305 days were affected by the interval from calving to first mastitis $(P<0.05$, Table 1$)$. The milk yields decreased when cows had mastitis early in lactation. Number of mastitis episode impacted the standardized 305-day milk yield and cows with one episode of mastitis produced more milk than those with repeated episodes of mastitis $(P<0.01)$. In addition to the herd effect, the cumulative first 100 days' milk production as well as the 305 -day adjusted milk yield were impacted by calving year and increased during 2001-2008 $(P<0.05)$.

Raw means for calving to conception interval and number of services per conception were 135.2 days and 2.33 during the period of 1994 to 2008 , respectively. Results for linear regression of proposed variables on these traits are shown in Table 2. Besides the herd effect, calving difficulty score impacted DO and SC $(P<0.01)$. The DO least square means were $110.4 \pm 16$ and $201.1 \pm 22$ days, respectively, for the cows with normal parturition compared to the abnormal parturition. Sex of calf and 60 days' milk production also impacted the DO $(P<0.05)$. Cows with male calves had a longer interval between calving and conception. The DO least square means were $155.75 \pm 16.9,192.33 \pm 17.4$, and $217.8 \pm 20.4$ days for cows with milk yield less than 1,644 , 1,645 to 2,036 , and more than $2,036 \mathrm{~kg}$, respectively. The $\mathrm{SC}$ were also impacted by calving season, number of mastitis episodes, and the interval between calving and first mastitis $(P<0.01)$. Increasing the number of mastitis episodes and decreasing the interval between first calving and mastitis increased services per conception $(P<0.001)$. In the mastitic cows, DO was not impacted by the mastitis episodes and the interval from calving to mastitis.

Results for linear regression of proposed variables on mastitis risk and calving to first mastitis interval are shown in Table 3. Mastitis incidence during the first lactation was increased over the period studied $(P<0.01)$. Normal parturition decreased the mastitis risk and the risk increased with increase in first cumulative 60 days' milk production $(P<$ $0.01)$. The interval between calving and first mastitis was impacted by calving season and was higher in winter compared with autumn $(P<0.01)$.

Variables affecting length of productive life and firstparity 30 DIM to culling (LPL30) are shown in Table 4. LPL was impacted by the sire origin, calving year, calving sex, and number of mastitis episodes $(P<0.05)$. Sire origin, calving year, calving difficulty score, calving sex, adjusted 305-day milk production, and number of mastitis incidences had a significant impact on LPL30 $(P<0.05)$. Mastitis tended to increase the chance of culling $(P=0.07)$. Survival
Table 1 Regression coefficients of variables that affected first cumulative 100 days' milk production and milk yield standardized to 305-day milk production in first-parity Holstein cows ${ }^{\mathrm{a}}$

${ }^{\mathrm{a} O n l y}$ main significant effects are included; $P \leq 0.05$; the dependent variables are italicized

\begin{tabular}{lrr}
\hline Term & Estimate & $P$ value \\
\hline First cumulative 100 days' milk production & & \\
Herd [4] & $-317.73 \pm 74.78$ & $<0.01$ \\
Calving year [2001-2008 vs. 1994-2000] & $230.01 \pm 89.75$ & 0.01 \\
Interval between first calving and mastitis[50 to 100 days & $256.88 \pm 110.10$ & 0.02 \\
vs. 10 to 50 days] & & \\
Milk yield standardized to 305-day milk production & $369.52 \pm 162.51$ & 0.02 \\
Herd [1] & $-1,077.68 \pm 179.68$ & $<0.01$ \\
Herd [4] & $633.02 \pm 218.38$ & $<0.01$ \\
Calving year [2001-2008 vs. 1994-2000] & $-704.66 \pm 248.46$ & $<0.01$ \\
Number of mastitis episode (2-5 times vs. 1 time) & $1,200.35 \pm 252.16$ & $<0.01$ \\
Interval between first calving and mastitis[more than 60 days & & \\
vs. 10 to 60 days] & & \\
\hline
\end{tabular}


Table 2 Regression coefficients of variables that affected calving to conception interval and services per conception in first-parity Holstein cows ${ }^{\mathrm{a}}$

\begin{tabular}{lrr}
\hline Term & Estimate & $P$ value \\
\hline Calving to conception interval & & \\
Herd [2] & $88.68 \pm 24.20$ & $<0.01$ \\
Herd [4] & $-47.88 \pm 21.08$ & 0.02 \\
Calving difficulty score (eutocia) & $-43.69 \pm 9.44$ & $<0.01$ \\
Sex of calf [male] & $10.09 \pm 4.95$ & 0.04 \\
Cumulative first 60 days' milk production (1,645-2,036 kg vs. & $31.61 \pm 11.52$ & 0.01 \\
less than 1,644 kg) & & \\
Services per conception & & \\
Herd [1] & $-0.99 \pm 0.28$ & $<0.01$ \\
Herd [2] & $1.57 \pm 0.65$ & 0.01 \\
Herd [4] & $-0.78 \pm 0.29$ & $<0.01$ \\
Calving difficulty score (eutocia) & $-0.67 \pm 0.24$ & $<0.01$ \\
Cumulative first 60 days' milk production (more than 2,036 kg vs. & $0.65 \pm 0.29$ & 0.02 \\
1,645-2,036 kg) & & \\
Calving season [autumn vs. summer] & $-0.59 \pm 0.29$ & $<0.05$ \\
Number of mastitis episode (more than one [2-5] vs. one episode of mastitis) & $1.03 \pm 0.27$ & $<0.01$ \\
Interval between first calving and mastitis[more than 60 days vs. & $0.81 \pm 0.26$ & $<0.01$ \\
10 to 60 days] & & \\
\hline
\end{tabular}

${ }^{a}$ Only main significant effects are included; $P \leq 0.05$; the dependent variables are italicized clinical mastitis in heifers in early lactation, declining as lactation proceeded. More than $50 \%$ of all clinical mastitis occurred in the first 3 weeks of lactation. The incidence of clinical mastitis in heifers at the beginning of lactation is higher than in older cows (McDougall et al. 2009; Piepers et al. 2009) and heifers have a higher incidence of environmental mastitis such as Streptococcus uberis than mature cows (McDougall et al. 2009).

Mastitis had a significant impact on milk yield. Heifers with more than one episode of mastitis after calving produced $12.5 \%$ less 305-day adjusted milk production than cows with one episode. It seems that the period of lactation modulates the impact of mastitis. The effects of mastitis on production yields are more severe when the mastitis
Table 3 Regression coefficients of variables that affect incidence of mastitis and calving to first mastitis interval in first-parity Holstein cows ${ }^{\mathrm{a}}$

${ }^{\mathrm{a} O n l y}$ main significant effects are included; $P \leq 0.05$; the dependent variables are italicized

\begin{tabular}{lrr}
\hline Term & Estimate & $P$ value \\
\hline Mastitis risk & & \\
Herd [2] & $0.45 \pm 0.19$ & 0.02 \\
Herd [4] & $-0.49 \pm 0.14$ & $<0.01$ \\
Calving year [2001-2008 vs. 1994-2000] & $-1.20 \pm 0.18$ & $<0.01$ \\
Calving difficulty score (eutocia) & $0.39 \pm 0.10$ & $<0.01$ \\
First cumulative 60 days' milk production (1,645-2,036 kg vs. & $-0.46 \pm 0.22$ & 0.03 \\
$\quad$ less than 1,645 kg) & & 0.01 \\
First cumulative 60 days' milk production (more than 2,036 kg vs. & $-0.79 \pm 0.32$ & \\
1,645-2,036 kg) & & \\
Calving to first mastitis interval & & \\
Herd [2] & $-24.81 \pm 13.23$ & 0.06 \\
Herd [4] & $42.50 \pm 11.12$ & $<0.01$ \\
Calving season [winter-autumn] & $42.65 \pm 14.16$ & $<0.01$ \\
\hline
\end{tabular}


Table 4 Regression coefficients of variables that affected first calving to culling interval and first parity 30 days in milk to culling in firstparity Holstein cows ${ }^{\mathrm{a}}$

\begin{tabular}{lcr}
\hline Term & Estimate & $P$ value \\
\hline Length of productive life & & \\
Origin of sire (Iranian sire) & $144.51 \pm 54.97$ & $<0.01$ \\
Calving year (2001-2008 vs. & $-333.99 \pm 84.01$ & $<0.01$ \\
$\quad$ 1994-2000) & $80.97 \pm 37.60$ & 0.03 \\
Sex of calf (male) & $-412.29 \pm 143.25$ & $<0.01$ \\
Number of mastitis episode & & \\
First parity 30 days in milk to culling & $145.84 \pm 54.92$ & $<0.01$ \\
Origin of sire (Iranian sire) & $-366.21 \pm 84.48$ & $<0.01$ \\
Calving year [2001-2008 vs. & $93.64 \pm 46.31$ & 0.04 \\
1994-2000] & $149.17 \pm 46.02$ & $<0.01$ \\
Calving difficulty score (eutocia) & $0.06 \pm 0.02$ & 0.01 \\
Sex of calf (male) & $-346.52 \pm 142.25$ & 0.02 \\
Adjusted 305-day milk production & & \\
Number of mastitis incidence & & \\
\hline
\end{tabular}

${ }^{a}$ Only main significant effects are included; $P \leq 0.05$; the dependent variables are italicized

developed in early lactation before the peak yield (Le Maréchal et al. 2011). In contrast to our results, Compton et al. (2007) did not find an association between the presence of clinical mastitis in the first 14 days of lactation and future milk production. It is possible that the pathogen causing the infection has an important impact on milk production and this may be responsible for the different results in the literature. It seems that neutrophil migration into parenchymal tissues and phagocytosis leads to lysis of mammary secretory tissue of multiparous lactating cows, likely resulting in decreased milk production (Piepers et al. 2009). Epigenetic modification, including

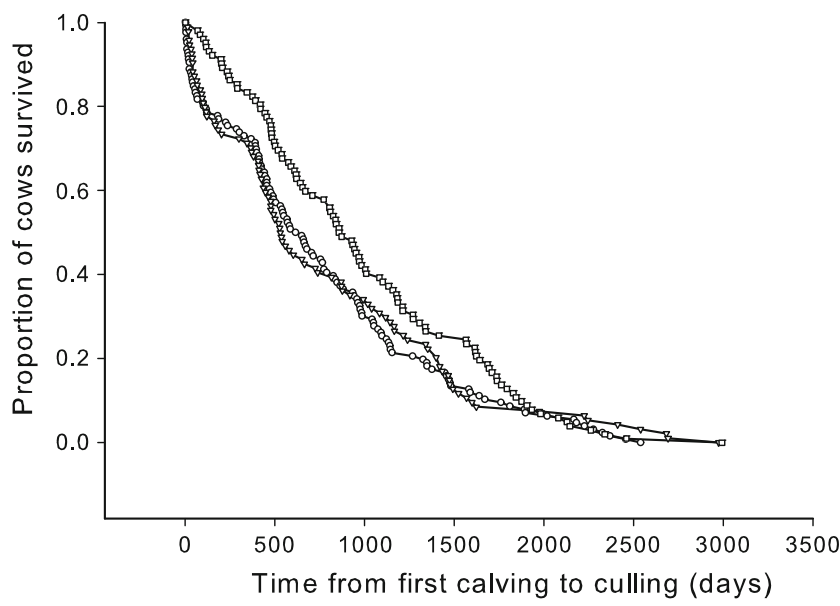

Fig. 1 Survival plot for cows with different intervals between calving and first mastitis (open circle less than 10 days, open triangle 10 to 60 days, and open square more than 60 days)
DNA methylation, has been studied recently to explain the impact of mastitis on milk production. DNA methylation, in addition to being a stable epigenetic event, may also play an acute regulatory role in gene transcription (Singh et al. 2010).

Increase in the number of mastitis episodes and decrease in interval between first calving and mastitis increased SC with no apparent impact on the DO. Some, but not all, farms have a voluntary waiting period after calving to breed cows and this could be the reason for the discrepancy on the effect of mastitis on SC and DO in this study. Impaired reproductive performance was also reported in other studies. A recent study showed that clinical mastitis occurring before first service postpartum significantly increased the days to first service, and consequently increased days to conception (Nava-Trujilloa et al. 2010). Their results suggest that the effects of clinical mastitis on reproductive performance (probably by affecting the hypothalamus-pituitary-ovary axis) in primiparous cows could be more severe, possibly due to certain characteristics of first calving cows such as more severe negative energy balance, poor dry matter intake, greater loss in body condition, lesser concentrations of glucose, insulin, and insulin-like growth factor-I. It was recently shown that negative energy balance mediates inhibition of the proinflammatory response, cell growth, and cellular development (Moyes et al. 2010). Increased incidence of miscarriage has also been reported in association with clinical mastitis (Chebel et al. 2004) as has reduced conception rate (Santos et al. 2004). Despite the recent studies on the impact of clinical mastitis on reproduction performance, Fourichon et al. (2000) reviewed 70 published papers and concluded that mastitis had no effect on reproduction.

The results of current study showed that mastitis incidence was greater in the high-producing cows, consistent with the findings of Hagnestam et al. (2007).

Results of the present study showed that normal calving decreased the mastitis risk. Metritis and endometritis are frequently observed due to dystocia. Cows that develop uterine disease experience a reduction in neutrophil function such as chemotaxis, phagocytosis, and killing ability around calving (Galvao et al. 2010). This may result in increasing the rate of udder infections due to immune suppression. They also reported a greater degree of negative energy balance and decreased lower intracellular PMN glycogen levels in cows with uterine disease, which could be a major predisposing factor for disease because of decreased availability of oxidative fuels.

In the present study, cows calved during the winter had a longer interval to first mastitis than those calved in autumn. In agreement with our results, another report showed for both heifers and multiparous cows, season of the year was significantly associated with the incidence of clinical mastitis (Steeneveld et al. 2008). Olde Riekerink (2007) also showed that season was associated with bulk milk somatic 
cell count, individual cow somatic cell count, and incidence rate of clinical mastitis. The prevalence of a pathogen at a specific time of year might explain a season effect on mastitis. Wenz et al. (2010) also recently showed that season might have resulted in lower concentrations of many of the innate immune response proteins. Thus, the higher concentrations of many of the proteins during the winter months could be linked to enhanced immune function associated with season. Improved neutrophil chemotaxis and lymphocyte proliferation may have resulted in an increased number of cytokine-producing leukocytes in the infected mammary gland (Wenz et al. 2010).

Although we did not see any sire origin effect on the number of mastitis episodes and calving to mastitis interval, sufficient evidence exists that genetic factors may control resistance or susceptibility to mastitis in dairy heifers (Detilleux 2009) and needs to be investigated.

Increase in the episodes of mastitis decreased the productive life. Our previous study showed that mastitis and unhealthy udders were major reasons for culling (Heravi Moussavi 2008). Chebel et al. (2004) showed that in multiparous cows and heifers, clinical mastitis around calving is associated with inferior reproductive performance, which may contribute to the high culling rate.

\section{Conclusion}

Clinical mastitis compromised lactation and reproduction performance, and most of the negative effect was observed when cows experienced their first clinical case early in lactation. Mastitis tended to increase the chance of culling and cows affected by mastitis left the herd earlier than control cows. Also, survival of cows in herd decreased when cows had mastitis early in lactation. Mastitis incidence increased and the interval between first calving and mastitis decreased in recent years. Hence, producers should pay extra attention to mastitis prevention and control programs, not only from the point of view of production and reproduction efficiency, but also the chance of increase in culling.

Acknowledgments This research was supported by Ferdowsi University of Mashhad.

Conflict of interest The authors declare that they have no conflict of interest.

\section{References}

Ahmadzadeh, A., Frago, F., Shafii, B., Dalton, J.C., Price, W.J. and McGuore, M.A., 2009. Effect of clinical mastitis and other diseases on reproductive performance of Holstein cows, Animal Reproduction Science, 112, 273-82
Chebel, R.C., Santos, J.E., Reynolds, J.P., Cerri, R.L., Juchem, S.O. and Overton, M., 2004. Factors affecting conception rate after artificial insemination and pregnancy loss in lactating dairy cows, Animal Reproduction Science, 84, 239-255

Compton, C.W.R., Heuer, C., Parker, K. and McDougall, S., 2007. Epidemiology of mastitis in pasture-grazed peripartum dairy heifers and its effects on productivity, Journal of Dairy Science, 90, 4157-4170

Detilleux, J., 2009. Genetic factors affecting susceptibility to udder pathogens, Veterinary Microbiology, 134,157-64

Fourichon, C., Seegers, H. and Malher, X., 2000. Effect of disease on reproduction in the dairy cow: a meta-analysis, Theriogenology, 53, 1729-1759

Galvao, K.N., Flaminio, M.J., Brittin, S.B., Sper, R., Fraga, M., Caixeta, L., Ricci, A., Guard, C.L., Butler, W.R. and Gilbert, R.O., 2010. Association between uterine disease and indicators of neutrophil and systemic energy status in lactating Holstein cows, Journal of Dairy Science, 93, 2926-2937

Hagnestam, C., Emanuelson, U. and Berglund, B., 2007. Yield Losses Associated with Clinical Mastitis Occurring in Different Weeks of Lactation, Journal of Dairy Science, 90, 2260-2270

Heravi Moussavi, A., 2008. Days in milk at culling in Holstein dairy cows, Journal of Animal and Veterinary Advances, 7, 89-93

Hertl, J.A., Grohn, Y.T., Leach, J.D.G., Bar, D., Bennett, G.J., Gonzalez, R.N., Rauch, B.J., Welcome, F.L., Tauer, L.W. and Schukken, Y.H., 2010. Effects of clinical mastitis caused by gram-positive and gram-negative bacteria and other organisms on the probability of conception in New York State Holstein dairy cows, Journal of Dairy Science, 93, 1551-1560

Hockett, M.E., Almeida, R.A., Rohrbach, N.R., Oliver, S.P., Dowlen, H.H. and Schrick, F.N., 2005. Effects of induced clinical mastitis during preovulation on endocrine and follicular function, Journal of Dairy Science, 88, 2422-2431

Huijps, K., De Vlieqher, S., Lam, T. and Hoqeveen, H., 2009. Cost estimation of heifer mastitis in early lactation by stochastic modeling, Veterinary Micribiology, 134, 121-127

Le Maréchal, C., Thiéry, R., Vautor, E. and Le Loir, Y., 2011. Mastitis impact on technological properties of milk and quality of milk products - a review, Dairy Science and Technology, 91, 247-282

McDougall, S., Parker, K.I., Heuer, C. and Compton, C.W.R., 2009. A review of prevention and control of heifer mastitis via nonantibiotic strategies, Veterinary Micribiology, 134, 177-185

Moyes, K.M., Drackley, J.K., Morin, D.E., Rodriguez-Zas, S.L., Everts, R.E., Lewin, H.A. and Loor, J.J., 2010. Mammary gene expression profiles during an intramammary challenge reveal potential mechanisms linking negative energy balance with impaired immune response. Physiological Genomics, 41, 161-170

Nava-Trujilloa, H., Soto-Bellosob, E. and Hoet, A.E., 2010. Effects of clinical mastitis from calving to first service on reproductive performance in dual-purpose cows, Animal Reproduction Science, $121,12-16$

Nyman, A.K., Ekman, T., Emanuelson, U., Gustafsson, A.H., Holtenius, K., Waller, K.P. and Sandgren, C.H., 2007. Risk factors associated with the incidence of veterinary-treated clinical mastitis in Swedish dairy herds with a high milk yield and a low prevalence of subclinical mastitis, Preventive Veterinary Medicine, 78, 142-160

Olde Riekerink, R.G.M., Barkema, H.W. and Stryhn, H., 2007. The effect of season on somatic cell count and the incidence of clinical mastitis, Journal of Dairy Science, 90, 1704-1715

Piepers, S., DeVliegher, S., deKruif, A., Opsomer, G. and Barkema, H. W., 2009. Impact of intramammary infections in dairy heifers on future udder health, milk production, and culling, Veterinary Microbiology, 134, 113-120

Santos, J.E.P., Cerri, R.L.A., Ballou, M.A., Higginbotham, G.E. and Kirk, J.H., 2004. Effect of timing of first clinical mastitis occurrence on lactational and reproductive performance of Holstein dairy cows, Animal Reproduction Science, 80, 31-45 
Singh, K., Erdman, R.A., Swanson, K.M., Molenaar, A.J., Maqbool, N.J., Wheeler, T.T., Arias, J.A., Quinn-Walsh, E.C. and Stelwagen, K., 2010. Epigenetic regulation of milk production in dairy cows, Journal of Mammary Gland Biology and Neoplasia, 15,101-112

Steeneveld, W., Hogeveen, H., Barkema, H.W., van den Broek, J. and Huirne, R.B.M., 2008. The Influence of Cow Factors on the
Incidence of Clinical Mastitis in Dairy Cows, Journal of Dairy Science, 91, 1391-1402

Wenz, J.R., Fox, L.K., Muller, F.J., Rinaldi, M., Zeng, R. and Bannerman, D.D., 2010. Factors associated with concentrations of select cytokine and acute phase proteins in dairy cows with naturally occurring clinical mastitis, Journal of Dairy Science, 93, 2458-2470 